\title{
Análisis constitucional de las normas concursales consagradas en la Ley de Garantías Mobiliarias ${ }^{1}$
}

\section{Constitutional analysis of the insolvency rules enforced in the Law of Security Rights Over Movables}

\section{Carlos Mario Montiel Fuentes ${ }^{2}$}

\section{RESUMEN}

Resulta importante realizar un breve análisis de constitucionalidad de las normas que han dado un giro inesperado en el régimen de insolvencia empresarial en Colombia. Se trata de la Ley de Garantías Mobiliarias (Ley 1676 de 2013), cuyas disposiciones referidas a los procesos concursales, a nuestro parecer, desconocieron algunos principios constitucionales y legales, así como los principios tradicionales del derecho concursal. El trabajo presentado incluye el alcance de las normas que tienen que ver directamente con el régimen de insolvencia empresarial en Colombia, los cargos de constitucionalidad que proponemos y que deben ser objeto de estudio, así como su desarrollo, y las conclusiones que arroja el estudio realizado.

1 Fecha de recepción: 14 de junio de 2018. Fecha de aceptación: 5 de diciembre de 2018 Para citar el artículo: Montiel C. "Análisis constitucional de las normas concursales consagradas en la ley de garantías mobiliarias". En Revist@ E-Mercatoria, vol. 17, n. ⒉ juliodiciembre 2018. DOI: https://doi.org/10.18601/16923960.v17n2.03

2 Abogado de la Universidad Externado de Colombia. Especialista en Derecho Comercial y Magister en Derecho Comercial de la misma Universidad. Docente Investigador del Departamento de Derecho Comercial de la Universidad Externado de Colombia y miembro de la línea de investigación Derecho de la Empresa, Crisis Empresarial y Costumbre Mercantil. Miembro del Instituto Iberoamericano de Derecho Concursal Capítulo Colombiano. Miembro de International Association of Restructuring, Insolvency \& Bankruptcy Professionals -Insol International- 
Palabras clave: Garantías, garantías mobiliarias, derecho concursal, insolvencia, principios, constitucionalidad, reorganización, liquidación judicial, teoría de los principios.

\begin{abstract}
It is important to conduct a brief analysis of the constitutionality of the rules that have taken an unexpected turn in the corporate insolvency regime in Colombia. This is the Law on Secured Transactions (Law 1676 of 2013), whose provisions referred to the insolvency proceedings, in our opinion, ignored some constitutional and legal principles, as well as the traditional principles of bankruptcy law. The work presented includes the scope of the rules that directly deal with the corporate insolvency regime in Colombia, the constitutionality charges that we propose and which should be the subject of study, as well as their development, and the conclusions drawn from the study carried out.
\end{abstract}

Keywords: Guarantees, bankruptcy, insolvency, principles, constitutionality, reorganization, liquidation, theory of principles.

\title{
SUMARIO
}

Introducción. 1. Normas objeto de análisis. 2. Alcance del Artículo 50 de la Ley 1676 de 2013: consideraciones generales. 2.1. Cargos de constitucionalidad propuestos. 2.2. Desarrollo de los cargos frente al artículo 50 de la Ley 1676 de 2013. 3. Alcance del artículo 51 de la Ley 1676 de 2013: consideraciones generales. 3.1. Cargos de constitucionalidad propuestos. 4. Alcance del artículo 52 de la Ley 1676 de 2013: consideraciones generales. 4.1. Cargos de constitucionalidad propuestos. Conclusiones generales

\section{INTRODUCCIÓN}

A propósito de la expedición de la denominada Ley de Garantías Mobiliarias, Ley 1676 de 2013, en la cual se incluyeron los artículos 50, 51 y 52, los cuales modifican sustancialmente el Régimen de Insolvencia Empresarial actualmente vigente en Colombia, se hace necesario realizar en esta ocasión, un análisis de constitucionalidad respecto de las mismas, por transgresión a varios principios de orden constitucional y principios de orden legal, lo cual conlleva a que dichas normas pierdan validez de interpretación. La Corte Constitucional ha construido una amplia doctrina sobre el principio de conservación de la empresa, la función social de la empresa, y sobre la empresa como una garantía institucional, lo cual a su vez se traduce en que el Legislador tiene límites en cuanto a su configuración legislativa cuando de afectar a una garantía institu- 
cional se trata, como lo es la empresa. La empresa se ha entendido como una necesidad para la sociedad, y no como un establecimiento más. Es el generador y multiplicador de riquezas en un estado social de derecho, desde el punto de vista de la generación de empleos, de la forma en que cómo se concreta el sector financiero en el sector real, y desde la manera en que se cumplen objetivos constitucionales a partir de la ejecución de su función social.

Los principios son orientadores del Legislador y por tanto deben ser tenidos en cuenta por éste al momento de la expedición de normas, máxime si se trata de una garantía institucional como la empresa. Consideramos que en el caso de los artículos 50, 51 y 52 de la Ley 1676 de 2013, el Legislador solo hizo uso de su libertad configurativa sin tener en cuenta aspectos adicionales que hoy por hoy ponen en riesgo a muchas empresas en recuperación, pero también transgreden el principio de igualdad, y afectan la protección del crédito de todos los acreedores, dándole beneficios significativos a otros, sin que exista, a nuestro parecer ninguna justificación justa y constitucional.

Por las anteriores razones, quisimos hacer un análisis de constitucionalidad de estas disposiciones, que desde ya anticipamos, arroja como resultado la inconstitucionalidad de las mismas, por cuanto viola principios de orden constitucional. En la presente entrega se hace una descripción de las normas objeto de análisis, para luego detallar los cargos de inconstitucionalidad que se proponen. Posteriormente, se desarrollan dichos cargos y se expresan, con base en una investigación y la inclusión de antecedentes jurisprudenciales constitucionales, los motivos por los deben ser considerados como inconstitucionales las normas ya mencionadas. El presente documento es el resultado de un trabajo de investigación realizado en torno a las disposiciones que consideramos inconstitucionales y no al mero criterio del autor. ${ }^{3}$

\section{NORMAS OBJETO DE ANÁLISIS}

Partiendo de un análisis previo de toda la teoría general de los principios propuesta por varios autores como Dwrkin, Robert Alexy y el profesor Carlos Bernal Pulido, y los principios de Derecho concursal, vamos a poner de presente las razones por las que los artículos 50, 51 y 52 de la Ley 1676 de 2013 desconocen principios de orden constitucional y algunos de orden legal y de paso transgreden a la empresa como garantía institucional.

3 De igual forma, se recomienda al lector del presente documento que en la medida de lo posible acuda al texto titulado "La Teoría de los Principios y los Principios del Derecho Concursal" del mismo autor, en el cual se detalla en mayor extensión la teoría constitucional y el fundamento histórico y constitucional de los principios y la teoría de los mismos. Este trabajo presenta un análisis de los cargos de inconstitucionalidad de los cuales pueden ser objetos las normas objeto de estudio. 
La metodología a seguir será, en primer lugar, hacer referencia a las normas que consagran la Ley de garantías mobiliarias que resultan problemáticas, ello contiene la transcripción literal de las mismas y el alcance que se deriva de su lectura, dado que es necesario que el juicio de constitucionalidad tenga elementos de certeza, es decir, que recaigan sobre una proposición real y existente y no sobre interpretaciones vagas, subjetivas e implícitas. En segundo lugar, se hará una relación de los argumentos y normas constitucionales violadas a grandes rasgos. En tercer lugar, pasaremos a analizar cada una de las normas constitucionales que resultan infringidas en términos de poder identificar el contenido material que se desprende de ellas, luego, diremos por qué dicho contenido resulta vulnerado por las normas de la Ley de garantías mobiliarias.

Esto siguiendo la jurisprudencia de la Corte Constitucional ${ }^{4}$ sobre los requisitos mínimos de una demanda de inconstitucionalidad.

Honrando el orden mencionado, pasamos a atisbar las normas que presentan problemas de exequibilidad para posteriormente efectuar el juicio de constitucionalidad de cada una a la luz de los principios señalados, esto es, el principio de universalidad objetiva, principio de universalidad subjetiva, principio de igualdad de trato y el principio de conservación de la empresa, excluyendo el principio de oficiosidad por las razones anotadas anteriormente. Se trata de los artículos 50, 51 y 52 de la Ley 1676 de 2013 o Ley de garantías mobiliarias, mediante los cuales se regula el tratamiento de las garantías en los procesos de insolvencia, entiéndase, en el proceso de reorganización empresarial y en el de liquidación judicial consagrados a su vez en la Ley 1116 de 2006. El primer proceso es de naturaleza recuperatoria y mediante él se busca la recuperación de empresas viables a través de la ccelebración de un acuerdo de reorganización entre los acreedores de la concursada, mientras que el segundo proceso es de naturaleza liquidatoria y pretende que se liquide el patrimonio de un deudor cuya recuperación no fue posible o que la actividad empresarial no era viable. Pasamos a transcribir los artículos mencionados.

"ARTÍCULO 50. LAS GARANTÍAS REALES EN LOS PROCESOS DE REORGANIZACIÓN. A partir de la fecha de inicio del proceso de reorganización no podrá admitirse ni continuarse demanda de ejecución o cualquier otro proceso de cobro en contra del deudor sobre bienes muebles o inmuebles necesarios para el desarrollo de la actividad económica del deudor y que bayan sido reportados por el deudor como tales dentro de la información presentada con la solicitud de inicio del proceso; con base en esta información se dará cumplimiento al numeral 9 del artículo 19 de la Ley 1116 de 2006.

Los demás procesos de ejecución de la garantía real sobre bienes no necesarios para la actividad económica del deudor, podrán continuar o iniciarse por decisión del acreedor garantizado.

4 Cfr. Corte Constitucional, Sentencia C - 1052 de 2001. Expediente n. ${ }^{\circ}$ D- 3472. 4 de octubre de 2001. M.P.: Manuel José Cepeda. 
El juez del concurso podrá autorizar la ejecución de garantías reales sobre cualduiera de los bienes del deudor, en los términos del artículo 17 de la Ley 1116, cuando estime, a solicitud del acreedor garantizado, que los citados bienes no son necesarios para la continuación de la actividad económica del deudor. También procederá la ejecución de los bienes dados en garantía cuando el juez del concurso estime que los bienes corren riesgo de deterioro o pérdida.

Los bienes en garantía reportados por el deudor al inicio del proceso de reorganización de que trata el inciso 10 de este artículo, deberán serpresentados en un estado de inventario debidamente valorado a la fecha de presentación de los estados financieros allegados con la solicitud.

En caso de que los bienes objeto de garantía estén sujetos a depreciación, el acreedor podrá solicitar al promotor $y$, en su caso, al juez del concurso, que se adopten medidas para proteger su posición de acreedor con garantía real, tales como la sustitución del bien objeto de la garantía por un bien equivalente, la dotación de reservas, o la realización de pagos periódicos para compensar al acreedor por la pérdida de valor del bien.

El promotor con base en esta información y demás documentos de prueba que aporte el acreedor garantizado, al presentar el proyecto de calificación y graduación y determinación de derechos de voto, reconocerá al acreedor garantizado el valor de la obligación como garantizada con los intereses inicialmente pactados basta la fecha de la celebración del acuerdo de reorganización y basta el tope del valor del bien dado en garantía.

Confirmado el acuerdo de reorganización, el acreedor garantizado tendrá derecho a que se pague su obligación con preferencia a los demás acreedores que bacen parte del acuerdo. Si el acreedor garantizado tuviere una obligación pactada a plazo, el pago se realizará en el plazo originalmente pactado y siempre y cuando se pague el monto vencido con anterioridad a la apertura del proceso de reorganización. Igual tratamiento tendrá el acreedor garantizado que accede a que se venda el bien dado en garantía como parte del acuerdo de reorganización.

Si el acreedor garantizado vota afirmativamente el acuerdo de reorganización y acepta que se pague su crédito en el marco del acuerdo de reorganización con una prelación distinta a la establecida en el inciso anterior, podrá solicitar que la obligación que no sea garantizada se reconozca como crédito garantizado basta el tope del valor del bien dado en garantía.

En caso de incumplimiento del acuerdo de reorganización, el liquidador en el proyecto de calificación y graduación de créditos reconocerá como obligación garantizada, el valor de la obligación basta el tope del valor del bien reportado a la fecha de la solicitud de apertura del proceso de reorganización si este es mayor.

En caso de no presentarse el acuerdo de reorganización o de su no confirmación, a la liquidación por adjudicación se aplicará lo dispuesto en el presente artículo para la liquidación judicial.

PARÁGRAFO. Las facilidades de pago de que trata el artículo 10 de la Ley 1116 de 2006, solo podrán referirse a las obligaciones por retenciones de carácter obligatorio a favor de las autoridades fiscales de conformidad con lo establecido en el artículo 32 de la Ley 1429 de 2010.

ARTÍCULO 51. LAS GARANTÍAS REALES EN LOS PROCESOS DE VALIDACIÓN DE ACUERDOS EXTRAJUDICIALES DE REORGANIZACIÓN. El tratamiento de las garantías reales en el proceso de reorganización empresarial también se aplicará en el proceso de validación judicial de acuerdos extrajudiciales de reorganización. 
ARTÍCULO 52. LAS GARANTÍAS REALES EN LOS PROCESOS DE LIQUIDACIÓN JUDICIAL. Los bienes en garantía de propiedad del deudor en liquidación judicial podrán excluirse de la masa de la liquidación en provecho de los acreedores garantizados o beneficiarios de la garantía siempre y cuando la garantía esté inscrita en el registro de garantías mobiliarias o en el registro que, de acuerdo con la clase de acto o con la naturaleza de los bienes, se bubiere becho conforme a la ley.

Si el valor del bien dado en garantía no supera o es inferior al valor de la obligación garantizada este bien podrá ser directamente adjudicado por el juez del concurso al acreedor garantizado.

Si el valor del bien supera el valor de la obligación garantizada, el producto de la enajenación se adjudicará en primera medida al acreedor garantizado y el remanente se aplicará a los demás acreedores en el orden de prelación legal correspondiente. El acreedor garantizado podrá optar por quedarse con el bien en garantía y pagar el saldo al liquidador para que lo aplique al pago de los demás acreedores.

De operar el pago por adjudicación, al acreedor garantizado se le adjudicará el bien basta concurrencia del valor de la obligación garantizada y el remanente será adjudicado a los demás acreedores en el orden de prelación legal.

En todo caso, lo establecido en el presente artículo no aplicará en detrimento de derechos pensionales.

PARÁGRAFO. La exclusión de los bienes en garantía en los procesos de liquidación judicial se bará sin perjuicio de los acuerdos que puedan celebrarse entre el acreedor garantizado y el liquidador, cuando los bienes en garantía bagan parte de la unidad de explotación económica del deudor y esta pueda venderse en los términos del parágrafo del artículo 81 de la Ley 1116 de 2006. Enajenado el bien en garantía el liquidador asignará al acreedor garantizado el valor del bien dado en garantía o podrá optar por pagar previo a la enajenación un importe equivalente al valor del bien dado en garantía y proceder a la enajenación en el curso del proceso.

\section{ALCANCE DEL ARTÍCULO 50 DE LA LEY 1676 DE 2013: CONSIDERACIONES GENERALES}

De la simple lectura del artículo 50 podemos extraer las siguientes generalidades:

a. No pueden promoverse procesos de cobro en contra del deudor sobre bienes necesarios para el desarrollo de la actividad económica del deudor, siempre y cuando así hayan sido reportados en la solicitud de admisión al proceso de reorganización. Esto es, que la norma de entrada diferencia a los bienes necesarios para el giro ordinario de los negocios de la compañía ${ }^{5}$, de

"Si bien el llamado giro ordinario de los negocios se encuentra determinado por las actividades que constituyen el objeto social, resultan oportunas algunas precisiones conceptuales en torno al empleo constante en la práctica mercantil de la referida expresión "giro ordinario de los negocios". Partiendo de las anteriores consideraciones en cuanto al tema del objeto social, se concluye que éste alude a las actividades que desarrolla o se propone 
los que no lo son, pero a su vez, la carga de informar cuáles tienen dicha calidad, es de la sociedad misma. Se desprende de la norma que, la información que allegue el deudor junto con la solicitud será la base para determinar si se informa o no a los jueces que tramitan procesos ejecutivos en los cuales se involucren dichos bienes.

b. El Juez del Concurso puede autorizar la ejecución, cuando lo estime, de bienes que no son necesarios para la continuación de la actividad económica del deudor o que corran riesgo de deterioro o pérdida. El Juez es el elegido por el Legislador para determinar si los bienes son o no necesarios para el giro ordinario de los negocios y cuándo corren riesgo de perderse o deteriorarse siempre y cuando se lo solicite el acreedor garantizado. Sin embargo nace una pregunta de esta cuestión y es de carácter procesal, en cuanto a si de dicha solicitud se correrá traslado al deudor y los demás acreedores o si por el contrario el Juez del Concurso decidirá sólo atendiendo a sus conocimientos sobre el asunto y a los argumentos que presente el interesado, esta pregunta no encuentra respuesta en la Ley y a nuestro parecer es uno de los tantos puntos objeto de complicaciones en el ejercicio práctico. Actualmente, la Superintendencia de Sociedades en su calidad de Juez del Concurso, ha tenido que basta con la relación del deudor en su solicitud de admisión al proceso de los bienes que son necesarios para el desarrollo de la actividad económica, para que sean considerados como tal. Esto, sin perjuicio de que esto pueda ser controvertido por el acreedor garantizado en su solicitud de ejecución.

c. El acreedor garantizado puede solicitar al Promotor y/o al Juez del Concurso que se le sustituya la garantía, que se realicen reservas a su favor o que se le hagan pagos periódicos para compensar la depreciación del bien. Entonces, cualquier acreedor garantizado podrá pedir el reemplazo de la que le fue dada al momento de contraer la obligación, o pedirle al deudor en concurso que le realice pagos periódicos para que no sufra un mayor daño, según dice la norma.

d. Entre otros aspectos, cuyo estudio se hará en adelante, el acreedor garantizado tiene derecho a que se le pague de manera preferente frente al resto de acreedores que hagan parte del acuerdo ${ }^{6}$. Pero si tiene una obligación a plazo,

realizar el ente social, al paso que solamente quedan cobijadas por " giro ordinario" aquellas actividades que en forma habitual u ordinaria, ejecuta la sociedad". Superintendencia de Sociedades. Oficio n. ${ }^{\circ} 220-75567$.

6 "De existir causales de preferencia el producto de la venta de los bienes del deudor debe ser destinado a pagar en primer lugar a los acreedores privilegiados. Surge entonces la figura de la prelación de créditos, la cual ha sido definida por la jurisprudencia constitucional como "(...) el conjunto de reglas que determinan el orden y la forma en que debe pagarse cada uno de ellos. Se trata entonces de una institución que rompe el principio de igualdad jurídica de los acreedores, de modo que debe ser interpretada restrictivamente, ya que no hay lugar a decretar preferencias por analogía; ${ }_{i}$ sólo existen aquellas expresamente contempladas en la ley". La Ley es la que determina en qué orden se han de satisfacer las acreencias "o sea que los particulares no pueden modificar la par conditio o el orden de 
deberá primero cancelársele lo vencido y seguir pagándosele en el plazo inicialmente pactado. Igual preferencia tendrá en el evento en que el proceso de reorganización fracase o se incumpla el acuerdo y se abra paso al liquidatorio.

\subsection{Cargos DE InCONSTITUCIONALIDAD PROPUESTOS}

Con relación al artículo 50 de la Ley 1676 evidenciamos tres cargos de constitucionalidad.

Primariamente, se vulneran los artículos 1 de la Constitución (respeto por el trabajo como fundamento del Estado Social de Derecho), 2 (deber de las autoridades de proteger los bienes de las personas), 53 (principios en materia laboral), 26 (libertad de profesión y oficio) y 334 en su inciso 2 (pleno empleo de recursos humanos) que se enfocan a la protección de los derechos de las personas al trabajo, su mínimo vital y su libertad de profesión.

Además, que el artículo 50 vulnera los artículos 1 (prevalencia del interés general, dignidad humana), 2 (prosperidad general), el 58 (interés público), el 95 (solidaridad), y 333 (interés general en la libre competencia, empresa como base del desarrollo), artículo 14 (derecho a la personalidad jurídica), artículo 16 (libre desarrollo de la personalidad), artículo 38 (derecho a la asociación), artículo 25 (derecho al trabajo), artículo 57 (estímulo a los trabajadores en la participación de la gestión de las empresas), artículo 60 (acceso a la propiedad) artículo 334 inciso 2 (promoción de la competitividad y productividad), relacionados con el interés general en la conservación de la empresa que fundamenta el principio de universalidad subjetiva y objetiva del derecho concursal.

Finalmente, se vulneran los artículos 13 (derecho a la igualdad), el preámbulo (fortalecimiento de la igualdad) que soportan el principio de igualdad de trato en materia concursal o par coditio creditorum, que a su vez es una de las razones de ser de los principios de universalidad en sus dos aristas.

\subsection{Desarkollo De los Cargos frente al artículo 50}

DE LA LEY 1676 DE 2013

a) Violación a los artículos 1, 2, 53, 26, 334 inciso 2: protección de los derechos de las personas al trabajo, su mínimo vital, su libertad de profesión y el deber que tiene el Estado de intervenir en la economía en desarrollo de promover el empleo.

Los artículos citados consagran un elemento material esencial de la Constitución que es el principio de protección al trabajador manifestado en sus derechos a obtener un mínimo vital y móvil y a la estabilidad en materia laboral,

prelación por pacto entre ellos". Corte Constitucional. Sentencia C-664 de 2006. M.P. Humberto Antonio Sierra Porto. 
es decir, la preservación de su empleo, también a la libertad de profesión u oficio, disposiciones éstas que deben ser prevalentes.

La importancia del contenido de las primeras normas ha sido señalado por la Corte así: "El trabajo tiene un carácter de derecho-deber y, como todo el tríptico económico de la carta -propiedad, trabajo, empresa-, cumple una función social. Es una actividad que goza en todas sus modalidades de la especial protección del Estado"7.

La protección del salario del trabajador se orienta a la satisfacción de sus necesidades básicas, lo que refuerza su dignidad humana y además le permite ejercer otros derechos conforme a un proyecto de vida. El salario es de tanta importancia que ha sido calificado por nuestra Corte como un derecho inalienable, ha sostenido "para el trabajador, recibir el salario -que debe ser proporcional a la cantidad y calidad del trabajo, como lo dispone el artículo 53 de la Constitución- es un derecho inalienable de la persona $y$, por ende, el pago del mismo es una obligación del patrono, que debe cumplir de manera completa y oportuna, a satisfacción del trabajador y de conformidad con lo acordado"s.

En materia concursal conforme a la prelación de créditos (2495 C.C) se consagra que los trabajadores hacen parte de la primera clase como manifestación de este principio de protección a la clase trabajadora, dados los derechos que se pueden ver afectados por el no pago de sus salarios y prestaciones sociales son fundamentales. Y es que la situación financiera crítica no es justificación para violar los derechos de los empleados. En este sentido se ha pronunciado la Corte en sentencia T-1284 de 2005, la disponibilidad presupuestal no justifica el no pago de las obligaciones, en especial cuando la omisión compromete la vida en condiciones dignas y justas de los trabajadores y pensionados.

De forma análoga, ha dicho en sentencia T- 229 de 2005: i) Los inconvenientes financieros del empleador o el hecho que se encuentre en un trámite concursal o liquidatorio no son razones que posean un alcance tal que liberen al empleador del pago de las prestaciones vinculadas a la relación de trabajo y con ello, disminuyan el nivel de protección de los derechos constitucionales de los trabajadores, ii) La necesidad de garantizar los derechos fundamentales de los trabajadores de la empresa en liquidación impone a su liquidador la obligación de adelantar las gestiones tendientes al pago de las acreencias laborales, entre ellas los aportes a la seguridad social ${ }^{10}$.

7 Colombia. Corte Constitucional. Sala Plena. Sentencia C- 221 de 1992. Expediente n. ${ }^{\circ}$ D- 006. 29 de mayo de 1992. M.P.: Alejandro Martínez Caballero.

8 Colombia. Corte Constitucional. Sala Quinta de Revisión. Expediente n. ${ }^{\circ}$ T- 49868. 22 de febrero de 1995. M.P.: Jose Gregorio Hernández Galindo.

9 Colombia. Corte Constitucional. Sala Octava de Revisión. Sentencia T- 1284 de 2005. Expediente n. ${ }^{\circ}$ T- 1175301.7 de diciembre de 2005. M.P.: Álvaro Tafur Galvis.

10 Colombia. Corte Constitucional. Sala Cuarta de Revisión. Sentencia C- 229 de 2005. 11 de marzo de 2005. Expediente n. ${ }^{\circ}$ T- 1000460. M.P.: Jaime Córdoba Triviño. 
A su vez, el pago de salarios se dirige a garantizar el mínimo vital de una persona su vida digna, por lo que afectándose el primero en reglas generales $y$ sin atender a un juicio en concreto si podemos decir que se afectan los demás, así lo ha establecido la Corte Constitucional, "a cada individuo que ingresa al mercado laboral -independientemente del estrato que ocupe-, recibe una retribución económica que, en principio, constituye la base de los gastos de manutención que plausiblemente espera cubrir y de las carencias que aspira superar. De abí, que la idea de un minimo de condiciones decorosas de vida (v.gr. vestido, alimentación, educación, salud, recreación), no va ligada sólo con una valoración numérica de las necesidades biológicas minimas por satisfacer para subsistir, sino con la apreciación material del valor de su trabajo, de las circunstancias propias de cada individuo, y del respeto por sus particulares condiciones de vida"11.

Sin embargo, el artículo 50 de la Ley 1676 de 2013 desconoce estos principios y derechos constitucionales a groso modo por dos razones. La primera se encamina a que al permitir la exclusión y la preferencia de los acreedores garantizados se les coloca en un nivel privilegiado en torno a los trabajadores, afectándose el principio de protección del trabajador que se enmarca en el derecho al pago de sus salarios y a condiciones de vida digna. El segundo, radica en que privilegiando a los acreedores garantizados afectamos la sostenibilidad de la empresa como se desarrollará en el siguiente cargo, pero lo que si se debe anotar con respecto a este es que desprotegemos al empleador porque no procuramos salvaguardar el lugar donde trabaja, y donde ejerce un oficio que a su vez perjudica su libre desarrollo de la personalidad y su libertad de profesión.

El primer argumento se sostiene con base en que si bien existía un régimen de prelación que reconocía a cabalidad los derechos de los trabajadores, puesto que pertenecían a la primera clase, abogando también por una igualdad real en que las personas que merecen especial protección la tienen, el artículo citado no procura esa satisfacción puesto que invierte la preferencia al excluir los bienes garantizados del concurso, optando por darle primacía al patrimonio de los grandes acreedores garantizados en lugar de proteger a los que merecen especial consideración que son los trabajadores.

A su vez, excluir estos bienes para el pago de los acreedores garantizados hace que el patrimonio se satisfaga para ellos y que siendo deudas de un valor alto después de suplidas sea poco probable que se tenga un haber para los trabajadores, y se anticipa, no solo para ellos, sino para el resto de acreedores. Pero ésta última anotación no debe ser vista como inespecífica, en tanto que es un hecho supuesto altamente probable pero aun aunque no consideráramos esta situación, en la abstracción de la legislación se debe perseguir la protección al trabajador y no son admisibles normas que puestas en práctica desconozcan los

11 Colombia. Corte Constitucional. Sentencia SU- 995 de 1999. Expedientes acumulados n. $^{\circ}$ T-218550 T-229080 T-233549 T-233551 T-233586 T-233681 T-233709 T-237521. 9 de diciembre de 1999. M.P.: Carlos Gaviria Díaz. 
derechos. Además, si colocamos nuestra mirada en los trabajadores que devengan un salario mínimo dentro de las empresas, el no pago de sus acreencias es una afectación directa e innegable a su mínimo vital, afectándoles gravemente y violando el régimen constitucional que los protegía ${ }^{12}$.

El segundo argumento ligado al anterior se basa en las pocas posibilidades que tiene una empresa de sobrevivir después de un proceso concursal basado en las reglas que dispuso o trajo consigo la Ley acusada en el presente documento (desarrollado a profundidad en el acápite siguiente) lo que priva al trabajador de la entidad donde desarrollaba sus labores, de las cuales se satisfacían él y su familia, y también conlleva un desconocimiento de sus derechos a la libertad de profesión porque sus posibilidades laborales se reducen en tanto que se convierte en una persona desempleada.

El Régimen de Insolvencia, en la modalidad de la reorganización, que perseguía la recuperación de empresas viables y que consagraba un equilibrio entre finalidades, léase la protección de la empresa, la protección del empleo y la protección del crédito, pasó a ser desequilibrada con ocasión de la expedición de la Ley 1676 por cuanto, sin justificación justa o fundamento constitucional se da una desproporcionada consagración a la protección del crédito. Y no a todos los créditos, solo a un sector de los acreedores, lo cual agrava esta circunstancia.

b) Violación de los artículos 1, 2, 58, 95, 14, 16, 38, 25, 57, 60, inciso 2 del artículo 334 y 333: principio de universalidad sustentado por el interés general de conservación de la empresa como segundo principio.

En este punto haremos referencia al contenido normativo de las disposiciones constitucionales que son relevantes para el análisis propuesto y las razones por las que éste contenido es desconocido por el artículo 50 de la Ley nombrada.

De los artículos 1 , 2 y 95 se desprende el elemento material del interés general en sentido amplio como un fundamento del Estado Social de Derecho que orienta a que conjuntamente atendamos prevalentemente a la satisfacción de necesidades que tiene toda la comunidad y que conllevan a la prosperidad general, hecho que para tornarse cierto requiere de solidaridad entre las personas asociadas al Estado.

Además, del artículo 58 y 333 se deriva que ante la existencia de conflictos de derechos entre los particulares el interés privado deberá ceder ante el interés público o social, particularmente en la actividad económica. Y de los artículos $14,16,38,25,57,60$ y el inciso 2 del artículo 334 desprendemos

12 Sostiene la sentencia T -891 de 2013: La relación entre salario mínimo y derecho al mínimo vital es innegable. El derecho al salario mínimo ha sido considerado un ingreso tan importante que tanto el Constituyente de 1991 como el legislador, le han dotado de una protección especial. Así, si bien no es sinónimo de mínimo vital, su afectación puede ponerlo seriamente en riesgo. Corte Constitucional. Sala Novena. Sentencia T- 891 de 2013. expediente T-3.977.302. 3 de diciembre de 2013. M.P.: Luis Ernesto Vargas. 
que la empresa constituye un escenario de satisfacción de intereses generales, porque surgida en ejercicio del derecho al libre desarrollo de la personalidad se estatuye como el lugar donde se brinda empleo y los derechos laborales de las personas son satisfechos. Ello por la concepción de la función social que se desprende de la empresa actualmente.

Esto se sustenta en la misma jurisprudencia de la Corte cuando dice que "La empresa, vista desde esta nueva perspectiva constitucional (esto es, vinculada por una función social), se erige, como el propio Estatuto Superior lo plantea, en base del desarrollo económico y, por ende, en fuerza motora del bienestar de los individuos [...] En efecto, la empresa se constituye en uno de esos ámbitos privilegiados dentro de los cuales la persona puede desarrollar su libertad y sus anbelos de realización a través del ejercicio de una profesión u oficio determinados. Es así como el valor del trabajo cobra una especial significación dentro del ámbito de la actividad empresarial".

Ahora, ¿Por qué tratar de manera conjunta estos dos principios? Recordemos que la universalidad tiene dos aristas, objetiva, todos los acreedores del deudor están llamados a formar parte del concurso, intervenir en él como el escenario único para obtener la satisfacción de sus acreencias y enfrentar las consecuencias legales adversas por el cualquiera que se la naturaleza de la obligación, el monto, la clasificación legal y la existencia o no de garantías ${ }^{13}$. Subjetiva, se vincula con el primero y es que perdiendo los acreedores el derecho de ejecución individual, en contraprestación se ha dispuesto que todo el patrimonio del deudor, no solo una parte de él, está comprometido en el proceso ${ }^{14}$.

No es posible entender el principio de universalidad sin la lectura del principio de conservación de la empresa como manifestación del interés general puesto que el último es un interés general que manifestado en la práctica orienta la organización y estructura del concurso en términos de igualdad en la manera en que lo refiere la universalidad. Esto lo sostenemos con base en la sentencia C- 854 de $2005^{15}$ en la cual expresó la Corte: "ba de entenderse que los procesos concursales, como procesos de carácter universal, no sólo se encaminan a bacer efectivas las obligaciones del deudor en estado de insolvencia, sino que persiguen, en lo fundamental, que la empresa que por diversas circunstancias se encuentre en él, no se vean avocadas de manera ineludible a su liquidación (negrillas fuera del texto original).

Es decir, se sustituyen los intereses particulares para obtener a toda costa el pago de obligaciones insolutas, por otro de interés general, de contenido social, a fin de que la empresa supere dificultades transitorias de afujías económicas, y continue con sus actividades, de las cuales no ba de beneficiarse únicamente el empresario sino la sociedad".

Ahora, este principio de universalidad es fundamentado en el interés general de preservar la empresa es vulnerado por el artículo 50 de la Ley citada. En lo 
que atiende a la universalidad objetiva por cuanto ya no es cierto que todo el patrimonio de deudor concursado quede afecto al proceso y a la satisfacción de las obligaciones respetando la prelación legal, pues en primera medida, los bienes objeto de garantía no harán parte del concurso, y en segunda, serán utilizados para pagarle a cualquier acreedor de cualquier clase, aún de manera preferencial frente a los trabajadores.

Por la forma en que se practica el tráfico mercantil en Colombia, los beneficiarios de lo preceptuado en las normas en comento serán las entidades financieras ${ }^{16}$, por cuanto los proveedores por cada factura que expidan no van a pedir una garantía, lo cual de hacerse, haría imposible el comercio. Mientras que los bancos, entidades financieras, entidades de financiamiento comercial o cualquier otra autorizada para colocar dineros, con el ánimo de no ser objeto de eventuales procesos de insolvencia, pedirán garantías reales en todo caso cuando se trate de otorgar y desembolsar un préstamo de dinero. Ahora bien, mucho menos un trabajador tendrá garantías reales, pero si en gracia de discusión alguien llegara a pensarlo, antes de la admisión al proceso de reorganización, dicho empleado estará por fuera de la empresa y sin obtener garantía alguna, esto, por razones obvias y propias de la naturaleza del contrato laboral.

Los procesos concursales dejaron de ser universales, por cuanto los bienes que constituyen el patrimonio del deudor no estarán en el concurso por haber sido entregados en garantía, es decir, de nada le sirve a una empresa ingresar el que antes sería un mecanismo recuperatorio y de protección, cuando sus bienes estarán desprovistos de dicha protección y dejarán de integrar la masa del concursado que garantizarían todas las obligaciones de los acreedores, y dicho sea de paso, garantizarían la continuidad de la actividad empresarial.

El hecho de que se sustraigan los bienes del concurso, hace que el mismo pierda credibilidad, que se estigmatice más aun de lo que en la actualidad está y que el resto de acreedores pierdan interés en apoyar un eventual acuerdo recuperatorio cuando saben que la compañía no cuenta siquiera con bienes que permitan garantizar sus obligaciones en una eventual liquidación.

Por otro lado, no sobra mencionar que en la mayoría de los casos, las entidades financieras reciben los bienes aplicándolos a las obligaciones por un menor valor que el que realmente tienen, que por lo general es el setenta por ciento $(70 \%)$, lo cual resulta bastante desafortunado tanto para el deudor como para el resto de acreedores.

Y que los bienes muebles, esto es, los que son susceptibles de garantías mobiliarias de los que trata la Ley configura según lo ha identificado la IFC (Corporación Financiera Internacional miembro del grupo Banco Mundial)

16 Esta afirmación encuentra soporte en que el artículo 1 de la Ley 1676 de 2013 expresa que "Las normas contenidas en la presente ley tiene como propósito incrementar el acceso al crédito...", es decir, que el cuerpo normativo tiene destinación específica y son las compañías encargadas y/o autorizadas para colocar productos de financiamiento o crediticios en el sector real. 
en su informe Doing Bussines ${ }^{17}$, el 95\% de los bienes de las micro, pequeñas y medianas empresas, por lo que nuestra preocupación de que la empresa sobreviva cuando en un proceso concursal se privilegia a los acreedores con garantías mobiliarias es fácticamente fundada. Esto es suficiente para pensar desde lejos, en un transgresión al principio de conservación de la empresa.

Además porque normalmente los bancos y/o las entidades financieras son quienes solicitan estas garantías, y las sociedades en Colombia cuentan con deudas elevadas por cuenta de créditos a los bancos. En aras a probarlo basta con revisar los niveles de endeudamiento de las sociedades del sector real, de cualquier sector para determinar que en la mayoría de las veces, su mayor endeudamiento es con las entidades financieras. Lo cual es apenas obvio, por cuanto se trata de que el sector financiero soporte el sector real.

En cuanto al principio de universalidad subjetiva, por cuanto, a los acreedores garantizados ya no les es aplicable la prelación legal, si tienen garantían no deberán ir al concurso a cobrar sus obligaciones en un único escenario y con el resto de acreedores. Si la obligación es pactada a plazo, ya no se extingue con la iniciación del proceso, sino que sus obligaciones podrán seguir siendo canceladas en el plazo establecido, no sin antes cancelárseles los montos vencidos.

Dejó de existir un único escenario universal al cual concurran todos los acreedores a fin de hacer valer sus obligaciones, y ahora existirán tantos como acreedores garantizados existan, pues cada uno podrá cobrar su obligación en el escenario que decida.

En el proceso concursal quedarán única y exclusivamente aquellos acreedores que no cuenten con garantías reales, que generalmente son los trabajadores y los proveedores de la compañía, a menos que éstos decidan empezar a solicitar garantías a sus clientes, caso en el cual, no pasará mucho tiempo para que sean ellos quienes deberán acceder a un mecanismo concursal, teniendo en cuenta las características del comercio en Colombia.

Esta consecuencia en el fondo lo que hace es perjudicar el interés general de poder salvaguardar la empresa como una actividad que promueve el empleo y es la base del desarrollo porque al privilegiar el interés particular de los Bancos como élite lo que hacemos es demandar que la empresa pague las más costosas deudas y acreencias que puede tener porque son con las entidades bancarias que cuentan con bienes garantizados, así toda posible salvación de la empresa es perdida y el motivo del concurso de desvirtúa.

c) Violación de los artículos 13 (derecho a la igualdad), el preámbulo (fortalecimiento de la igualdad): principio de igualdad de trato en materia concursal o par coditio creditorum.

17 En: Red de Cámaras de Comercio: Confecámaras. Registro de garantías mobiliarias. Disponible en https://www.garantiasmobiliarias.com.co/Informacion/RGM.aspx [Citado el 16 de septiembre de 2017]. 
En este aparte nos referiremos a los elementos materiales del texto constitucional que son pertinentes para el análisis propuesto y las razones por las que éste contenido es desconocido por el artículo 50 de la citada Ley.

El preámbulo de la Constitución señala que uno de los fines de la Carta es asegurar la igualdad. El artículo 13 consagra el principio de igualdad ante la Ley y prohíbe la discriminación por criterios "sospechosos" en su primer inciso, en el segundo y tercero señala la labor que debe tener el Estado tiene de propiciar una igualdad real y efectiva sobre todo en tratándose de personas en debilidad manifiesta, o que tradicionalmente han sido marginados.

La Corte Constitucional ha señalado que del contenido del artículo 13 se descomponen cuatro mandatos: (i) un mandato de trato idéntico a destinatarios que se encuentren en circunstancias idénticas, (ii) un mandato de trato enteramente diferenciado a destinatarios cuyas situaciones no comparten ningún elemento en común, (iii) un mandato de trato paritario a destinatarios cuyas situaciones presenten similitudes y diferencias, pero las similitudes sean más relevantes a pesar de las diferencias y, (iv) un mandato de trato diferenciado a destinatarios que se encuentren también en una posición en parte similar y en parte diversa, pero en cuyo caso las diferencias sean más relevantes que las similitudes.

Estos cuatro contenidos tienen sustento en el artículo 13 constitucional, pues mientras el inciso primero del citado precepto señala la igualdad de protección, de trato y en el goce de derechos, libertades y oportunidades, al igual que la prohibición de discriminación, los incisos segundo y tercero contienen mandatos específicos de trato diferenciado a favor de ciertos grupos marginados, discriminados o especialmente vulnerables ${ }^{18}$.

En este mandato de igualdad del artículo 13 se ha desarrollado la par conditio creditorem imponiendo una igualdad entre iguales. Así, se establece un mismo trato para los acreedores del mismo grado de prelación y a su vez estos grados se dirigen a dar un tratamiento diferenciado a la luz del principio de igualdad, por ejemplo, la Ley establece dentro del primer grado a los trabajadores que son personas que merecen una protección especial dada su condición de subordinación y que su mínimo vital se satisface con la realización de labores por regla general.

El principio se ve relacionado con la universalidad que anotamos como trasgredido también por la legislación, dado que para garantizar la igualdad en el paso de las acreencias se pierde la posibilidad de ejecución individual ${ }^{19}$ concurriendo todos a un proceso concursal e impidiendo la posibilidad de

18 Corte Constitucional. Sentencia C-818 de 2010. M.P. Humberto Antonio Sierra Porto. Óp. cit.

19 Dijo la Corte en que una manifestación del principio de igualdad es la prohibición de realizar ejecuciones singulares. Colombia. Corte Constitucional. Sentencia T -1017 de 2002. Óp. cit. 
cancelar deudas de obligaciones anteriores, precisamente para que en un escenario equitativo se ordenen los pagos. En este sentido se pronunció la Corte Constitucional interpretando la Ley 222 de 1995 "con el fin de proteger el derecho a la igualdad de todos los acreedores, incluidos los de primer orden -los pensionados-, el representante legal de la compañía concursada queda impedido para realizar, por fuera del proceso concursal, cualquier pago de obligaciones anteriores a la apertura del trámite liquidatorio so pena que los pagos sean ineficaces de pleno derecho (L. 222/95, art. 98, nl. 3). Esta medida se justifica en tanto el proceso liquidatorio busca el pago ordenado de las acreencias, de acuerdo con la prevalencia de los acreedores que tienen derechos preferenciales, en condiciones de igualdad"20

Además, refiriéndose esta vez al trámite de reestructuración ha resaltado la Corte la importancia del principio de igualdad que conjuntamente con el principio del interés general en torno a la conservación de la empresa que conlleva la procura de su salvación en momentos de crisis, al que se hizo alusión, desprenden a su vez el principio de pago ordenado y proporcional, por lo que notamos como el invocado imperativo tiene un sustento de principio constitucional. Ha dicho "La disposición de suficientes berramientas para garantizar la igualdad de los acreedores durante el trámite de la reestructuración, sumada al compromiso del Estado de darle prevalencia al interés general en el desarrollo de dichos procesos, permite concluir que la realización de pagos por fuera del acuerdo de reestructuración, cuando los mismos no obedecen al giro ordinario de los negocios del agente económico, resulta constitucionalmente insostenible. Primero, porque desconoce el derecho a la igualdad de trato de los otros acreedores en la medida en que burla la prelación y el principio de pago ordenado y proporcional, y segundo, porque distorsiona la finalidad del acuerdo y puede llegar a desestabilizar las proyecciones financieras del caso, en desconocimiento del interés general que la recuperación o el saneamiento fiscal del agente económico reporta ${ }^{21}$.

Ahora, el hecho de que la preferencia sea dada por la Ley no se vuelve un mérito para decir que el fundamento aludido no es pertinente por no tener naturaleza constitucional, puesto que aunque se encuentra en la Ley, su existencia se desprende directamente del principio constitucional de igualdad por lo que es una manera de materializarlo en materia concursal. Y así lo ha señalado la Corporación refiriéndose al tema de los pensionados "En desarrollo del principio constitucional de igualdad, la Ley otorga carácter preferencial a las acreencias laborales. Por ello, a los pensionados de una empresa en liquidación obligatoria que no dispone de los recursos suficientes para cumplir siquiera con las obligaciones preferentes en materia pensional, les asiste el derecho de beneficiarse, en igualdad de condiciones, de la distribución de los activos disponibles en la liquidación"

Asentando el análisis, pasamos a relacionar los argumentos que soportan la inconstitucionalidad de la medida: 
i) Todos los acreedores dejan de ser vinculados al proceso, para darle paso a un trato diferencial, preferencial y ya no igualitario que al resto de acreedores. Desaparece frente a ellos, la prelación legal y no les corresponde llegar al concurso. Las cláusulas que se dispongan en un eventual acuerdo de reorganización, les dejará de ser aplicables por cuanto no hacen parte de dicho escenario para cobrar las obligaciones a su favor y poco o nada les importa lo que se estipule en un acuerdo que no los vincula.

ii) Deja de respetarse la prelación legal frente a los acreedores garantizados y las condiciones que se establezcan para la satisfacción de las obligaciones, si bien tendrían que ser iguales para todos los que tengan una misma clase, en este caso, los acreedores garantizados dejan de pertenecer a una clase cualquiera para estar por encima de todas, aún de la primera clase que incluye trabajadores y acreencias fiscales (se excluyen pensionados).

Si bien este principio rige, como lo manifiesta el profesor Rodríguez Espitia, en forma estratificada al interior de cada clase de créditos, para los acreedores con garantía real, dejaron de existir los estratos que habían existido hasta el momento, para crearse a su favor una especie de supra estratos, donde ni siquiera tendrán que acudir al proceso concursal. Supra estrato que desde cualquier punto de vista coincide con la situación económica de quienes suelen ser los acreedores con garantía real.

iii) Deja de existir la concepción tradicional de igualdad y el interés mayor de algunos acreedores que se encuentran en primera clase y a los cuales debe garantizárseles su prelación con el fin de resguardar sus derechos fundamentales, para abrirle paso a otros que por el hecho de tener garantías reales, tendrán preferencia por encima de los preceptos constitucionales y de la jurisprudencia constitucional, según la cual los trabajadores gozan de especial protección y tienen derechos que pueden ir más allá del concurso mismo, pero atendiendo a su condición de empleados cuya fuente de ingresos y subsistencia propia y de sus familias, es el salario que reciben, y no, atendiendo a una mera apreciación subjetiva del Legislador que carece de cualquier sustento jurídico y constitucional, por cuanto parece tener la creencia que una garantía real otorga derechos supraconstitucionales que desdibujan y desnaturalizan el derecho concursal como disciplina jurídica y viola derechos fundamentales.

Cuando explicábamos el principio de igualdad de trato mencionábamos las manifestaciones que tenía en materia concursal, podemos traer algunas y notar son totalmente trasgredidas, al punto de una trasgresión manifiesta del principio:

- Que todos los acreedores deben concurrir al proceso: Esto dejó de ser cierto, por cuanto los acreedores con garantía real no deben hacerlo. 
- Todos los acreedores tendrán un tratamiento equitativo: Esto dejó de ser cierto por cuanto los acreedores no tienen tratamiento equitativo frente a los que cuentan con garantías reales. Ni siquiera los trabajadores.

- El acuerdo de reorganización dispondrá un mismo trato para todos los acreedores de una misma clase o grado: Esto dejó de ser cierto, por cuanto en la gran mayoría de casos los acuerdos de reorganización no los vinculará por contar con un escenario aparte del concurso para hacer valer sus acreencias.

- Podrá impugnarse el acuerdo cuando no sean incluidos todos los acreedores anteriores a la iniciación del proceso: Esto dejó de ser cierto, pues los acreedores con garantías reales podrán no ser incluidos dentro del acuerdo, a pesar de ser anteriores al inicio del proceso de reorganización.

- Podrá impugnarse el acuerdo cuando contenga estipulaciones que impliquen un trato desigual a acreedores de la misma clase: Esto dejó de ser cierto, por cuanto los acreedores con garantías reales tendrán un trato desigual otorgado por la Ley misma.

Ahora, recordemos que la violación de un principio de igualdad se ha desarrollado dentro de la jurisprudencia de la Corte al lado de un test de igualdad que en última medida ha pasado a llamarse juicio "integrado de igualdad". En el caso que nos atiende vamos a analizar cómo no solo en primera medida argumentamos una violación al principio de igualdad sino que si examinamos las causas que dan origen a la diferenciación encontramos que no existe proporcionalidad.

En primera medida, habíamos dicho que el test de igualdad tiene diversas intensidades dependiendo de la materia que se trate. En el presente caso estamos frente a un evento de afectación prima facie de los derechos fundamentales de los trabajadores que a la vez se torna un privilegio para los acreedores garantizados por lo que haremos uso del test estricto.

Este test busca establecer 1. Si el fin es legítimo, importante e imperioso 2. Si el medio es legítimo, adecuado y necesario, es decir, si no puede ser remplazado por otro menos lesivo. 3. Si los beneficios de adoptar la medida exceden claramente las restricciones impuestas sobre otros principios y valores constitucionales, es decir, que la medida no resulte evidentemente desproporcionada frente al derecho sacrificado ${ }^{23}$.

En primer lugar, la finalidad que ha mencionado la doctrina que puede tener la Ley es principalmente facilitar el acceso al crédito de las empresas, particularmente a las más pequeñas, puesto que si se conoce que el riesgo de incumplimiento de una obligación puede ser cubierto de forma rápida y efectiva por medio de una garantía y existe un riesgo de pérdida o de incumplimiento 
para el acreedor, debería reducir la tasa de interés de un crédito garantizado ${ }^{24}$. Este fin podría considerarse como legítimo e importante dado que busca promover el acceso a la propiedad (art. 60) y la libre competencia (art. 333) permitiendo que al facilitarse el acceso al crédito que se tenga mayor capital para crear empresas y mejorar la productividad de las mismas, por lo que el elemento inicial se vería satisfecho, siempre y cuando se viera reflejado en la realidad, lo cual no ha sido así. Con ocasión de la expedición de la Ley no se han disminuido las tasas de interés, no se ha aumentado el crédito a pequeñas empresas, y las políticas de colocación siguen siendo las mismas. En cambio, si se ha mejorado la posición de ciertos acreedores en un proceso concursal, el cual debe ser universal e igualitario entre sus acreedores.

En segundo lugar, en torno al elemento de necesidad hay que anotar que la Ley en busca de ese propósito extiende los bienes que son susceptibles de garantía y siendo bienes sin tenencia lo que permiten es que los deudores puedan pagar sus obligaciones con el producto que obtengan del uso y aprovechamiento del bien y a su vez, lo que constituye el aspecto problemático de constitucionalidad, excluye a los bienes garantizados del concurso. La última novedad reduce ampliamente las opciones de salvamento de una empresa como lo anotamos y también el principio de protección al trabajador en cuanto al ejercicio de sus derechos irrenunciables al salario y a sus prestaciones sociales, además la reducción tajante de probabilidades de conservación de la empresa conllevaría a que terminara liquidándose y se afectan también los derechos de los trabajadores.

Podemos ver que la afectación a los derechos de protección al trabajador, que son principios constitucionales, aunado al perjuicio que se ocasiona el principio de conservación de la empresa y al principio de universalidad es bastante alto sobre todo si consideramos que realmente las medidas para obtener el fin podrían ser menos lesivas.

Lo anterior en cuanto a que la sola ampliación de los bienes a garantizar sin que el deudor se desprendiera de la misma ya era una medida para facilitar el crédito y ella no transgrede los principios que anotamos. Una medida diferente es una que se ha venido utilizando y que ha dado buenos resultados, por lo que podría haberse fomentado, Bester la explica así: consiste en intervenciones como las garantías parciales de crédito respaldadas por el gobierno que se entregan a través del FNG, orientadas a facilitar el acceso al crédito de las empresas más pequeñas que tienen potencial de crecimiento pero se ven racionadas de los mercados financieros por problemas de información y de incentivos, parecen una política potencialmente eficiente: al actuar como garante de una fracción del crédito, el gobierno levanta la restricción crediticia

24 BonILLA, FABIO ANDRÉS. El nuevo régimen legal de garantías Revista e- mercatoria. Bogotá D.C. 2014. p. 42 
de las empresas más pequeñas. El gobierno terceriza la originación o colocación de los créditos con intermediarios privados, lo que aumenta la eficiencia de la operación, y al garantizar sólo parcialmente el crédito, asegura que el prestamista retenga algún riesgo, de modo que tenga el incentivo de conducir una evaluación adecuada del crédito ${ }^{25}$

Además, si nos centramos en que la facilitación del acceso al crédito tiene como fundamento propiciar el desarrollo económico a través de la actividad de pequeñas empresas, podrían haberse diseñado políticas de reducciones a la tributación. Sobre las políticas de reducciones a la tributación, con seguridad una reducción uniforme de la tasa del impuesto de renta que cobije por igual a todas las empresas obligadas a declarar y una simplificación del sistema tributario que elimine los tratamientos preferenciales, favorecería la actividad empresarial, entre otras porque garantizaría a las empresas la posibilidad de competir en igualdad de condiciones en el mercado ${ }^{26}$.

Por lo tanto, se puede concluir que pese a que la finalidad que pretende alcanzar la medida de preferencia a los acreedores de garantías mobiliarias es constitucional e importante no es necesaria en tanto que existen medidas menos lesivas para los principios citados que atenderían al cumplimiento de las mismas, por lo que la norma es inconstitucional por no ser proporcional y ocasionar una violación al derecho de igualdad.

\section{ALCANCE DEL ARTÍCULO 51 DE LA LEY 1676 DE 2013 : CONSIDERACIONES GENERALES}

Se extrae del artículo 51 de la Ley 1676 de 2013 que todo lo aplicable al proceso de reorganización, tendrá aplicación al proceso de validación judicial de acuerdos extrajudiciales que regula el artículo 84 de la Ley 1116 de 2006. Por lo que en los acuerdos extrajudiciales las consideraciones que se dilucidan de la lectura de la norma son las mismas que se previeron para el artículo 50 anterior.

\subsection{CARGOS DE INCONSTITUCIONALIDAD PROPUESTOS}

Al artículo 51 de la Ley 1676 por serle aplicables las normas del artículo 50 merecen las mismas consideraciones que el cargo del artículo anterior. Por lo que extendemos nuestros argumentos al mencionado también.

25 Bester. En: MeléndeZ, Marcela. Acceso al financiamiento de la pequeña y mediana empresa en Colombia: retos de política pública. CAF Working Papers. Colombia. 2011. p. 20 ,

26 MelÉndeZ, MARCELA. Acceso al financiamiento de la pequeña y mediana empresa en Colombia: retos de política pública. Óp. cit. p. 32. 


\section{ALCANCE DEL ARTÍCULO 52 DE LA LEY 1676 \\ DE 2013 : CONSIDERACIONES GENERALES}

Del artículo 52 de la Ley 1673 de 2013 se desprenden dos grandes consecuencias. De un lado que los bienes del deudor dados en garantía, se excluyen de la masa liquidatoria en favor de los acreedores garantizados. Aunque si el valor del bien no supera el valor de la obligación garantizada, podrá ser adjudicado al acreedor, en caso contrario podrá ser rematado y el remanente será parte de la masa. Aunque el acreedor puede decidir quedarse con el bien y pagar la diferencia al liquidador para que haga parte del concurso. Del otro, que lo dispuesto en la norma, no incluye única y exclusivamente a los pensionados.

\subsection{Cargos De inCONSTITUCIONALIDAD PROPUESTOS}

En razón a que hemos expuesto en las consideraciones generales del artículo 52 , el contenido que objetamos como inconstitucional es el mismo y los cargos para esta norma serían idénticos que los utilizados para el artículo 50, máxime si se tiene en cuenta que el análisis se ha hecho desde una confrontación frente a los principios, y no refiriéndonos a un caso en particular de violación de derechos fundamentales.

\section{CONCLUSIONES GENERALES}

En el documento que ha sido objeto de entrega en esta oportunidad, como un artículo de investigación, hemos querido realizar un análisis particular de las normas incluidas en la Ley de Garantías Mobiliarias (Ley 1676 de 2013) que directamente tienen que ver con los procesos concursales en Colombia, o más bien, con el Régimen de Insolvencia Empresarial, el cual desembocó en que dichas normas resultan contradictorias a los principios que deberían servir como directrices inspiradoras al Legislador, a los principios de orden Constitucional, y a los principios de orden legal, razón por la cual deben ser excluidas del ordenamiento, a través de la declaratoria de inexequibilidad por parte de la Corte Constitucional.

Las normas objeto de estudio, en primer lugar, transgreden directamente preceptos constitucionales que a su vez consagran garantías institucionales y reconocidas como tal en la jurisprudencia constitucional. La empresa ha sido un pilar esencial para la economía, una necesidad para la sociedad, y el motor y núcleo esencial de la generación de riqueza, todo lo cual ha sido echado de menos por parte del Legislador cuando expidió la Ley en comento. No solo no tuvo en cuenta los principios que rigen el establecimiento constitucional, sino los principios que inspiran al legislador, y de paso, la amplia jurisprudencia constitucional que ha protegido en demasía a la empresa. 
Por otro lado el derecho concursal quedó huérfano con las disposiciones objeto de análisis, en tanto se contrarían los principios clásicos reconocidos para la materia, y las finalidades de un régimen de insolvencia pueden verse inanes frente a una legislación especial y posterior de este tipo, donde desconoce la naturaleza propia de los procesos universales al cual deben concurrir los acreedores a reclamar sus acreencias. En Colombia han venido, injustificadamente a nuestro parecer, creando excepciones al derecho concursal mediante la expedición de decretos y desconociendo la aplicación directa de principios al momento de crear las normas, interpretarlas y aplicarlas, con el fin de beneficiar a ciertos sectores, a propósito o no, o por seguir estándares internacionales, pero que en todo caso están afectando a la empresa, que como hemos insistido, cuenta con especial protección constitucional.

Lo cierto es, que con la expedición de los artículos 50, 51 y 52 de la Ley 1676 de 2013, sí se han beneficiado a acreedores, sin que exista justificación constitucional ni legal, y dichos acreedores son aquellos que por su esencia están capacitados y/o autorizados para otorgar créditos, léase, las entidades financieras o de financiamiento comercial. En otras palabras, el sector financiero. Como fue explicado en el curso de este escrito, es inicuo tan solo pensar que otro tipo de acreedor como los laborales, los proveedores estratégicos con quien se sostienen relaciones comerciales diarias en las que media solo una orden de compra o factura, soliciten garantías mobiliarias o de otro tipo; se insiste una vez más que ello haría imposible el tráfico jurídico mercantil en el país. 